\title{
Estimating Tunnel Strain in the Weak and Schistose Rock Mass Influenced by Stress Anisotropy: An Evaluation Based on Three Tunnel Cases from Nepal
}

\author{
Krishna Kanta Panthi ${ }^{1} \cdot$ Pawan Kumar Shrestha ${ }^{2}$ \\ Received: 7 February 2017 / Accepted: 1 March 2018 / Published online: 6 March 2018 \\ (c) The Author(s) 2018. This article is an open access publication
}

\begin{abstract}
Total plastic deformation in tunnels passing through weak and schistose rock mass consists of both time-independent and time-dependent deformations. The extent of this total deformation is heavily influenced by the rock mass deformability properties and in situ stress condition prevailing in the area. If in situ stress is not isotropic, the deformation magnitude is not only different along the longitudinal alignment but also along the periphery of the tunnel wall. This manuscript first evaluates the long-term plastic deformation records of three tunnel projects from the Nepal Himalaya and identifies interlink between the time-independent and time-dependent deformations using the convergence law proposed by Sulem et al. (Int J Rock Mech Min Sci Geomech 24(3):145-154, 1987a, Int J Rock Mech Min Sci Geomech 24(3):155-164, 1987b). Secondly, the manuscript attempts to establish a correlation between plastic deformations (tunnel strain) and rock mass deformable properties, support pressure and in situ stress conditions. Finally, patterns of time-independent and time-dependent plastic deformations are also evaluated and discussed. The long-term plastic deformation records of 24 tunnel sections representing four different rock types of three different headrace tunnel cases from Nepal Himalaya are extensively used in this endeavor. The authors believe that the proposed findings will be a step further in analysis of plastic deformations in tunnels passing through weak and schistose rock mass and along the anisotropic stress conditions.
\end{abstract}

Keywords Tunnel strain $\cdot$ Instantaneous and final deformation $\cdot$ In situ stress $\cdot$ Himalayan geology

\section{Introduction}

Stability of tunnels passing through weak and schistose rock mass is influenced by two important considerations, which are assessment of extent of tunnel deformation and requirement of support pressure (stiffness) to contain the deformation. Tunnel deformation in weak and schistose rock mass mainly consists of time-independent and timedependent deformations. For a long-term stable tunnel, support design should be made by considering both deformation

Krishna Kanta Panthi

krishna.panthi@ntnu.no

Pawan Kumar Shrestha pawan304@gmail.com

1 Norwegian University of Science and Technology (NTNU), Trondheim, Norway

2 Hydro Tunneling and Research Private Limited, Kathmandu, Nepal types. Traditionally, rock support interaction (Panet 1995, 2001; Carranza-Torres and Fairhurst 2000; Oreste 2009) is practiced to optimize rock support requirement in tunnels passing through weak and schistose rock mass experiencing plastic deformation. The 'rock support interaction analysis' assumes that the time-independent maximum deformation takes place when the tunnel face effect has ceased. However, time-dependent deformation around the tunnel periphery will continue for long time even after the excavation elapses. According to Sulem et al. (1987a) and Kontogianni et al. (2006) the magnitude of time-dependent deformation has in some occasion reached over half of the total deformation recorded during long time span. Therefore, it is extremely important to consider both time-dependent and time-independent deformations while designing tunnel rock support for tunnels passing through schistose and plastically deformable rock mass. In an advancing tunnel passing through such rock mass, the tunnel instrumentation and monitoring programs are the part of tunneling cycle and tunnel convergences are in general continuously recorded. When tunnel 
convergence against time of excavation and distance from the tunnel face are systematically recorded, time-independent and time-dependent deformations in tunnel can be estimated using the convergence law proposed by Sulem et al. (1987a, b). Similarly, Wang et al. (2014) had proposed an analytical formulation for the stress and displacement fields in the host rock and in the liners by accounting sequential excavation for lined circular tunnels excavated in viscoelastic rock and supported by any number of elastic liners installed at various stages. Their approach is relevant and applicable to a tunnel of large cross-sectional area where sequential excavation method is applied. However, none of the cases presented in this manuscript are excavated using sequential method of excavation.

Hence, the scope of this manuscript is therefore to review, analyze and discuss the extent of time-independent and timedependent deformations along the headrace tunnel sections of three hydropower projects passing through weak, schistose and deformable rock mass. Relation between time-independent (instantaneous) and total tunnel deformation (tunnel strain), and rock mass deformability properties, in situ stress and support pressure is established and discussed. To achieve this goal, the actually measured deformation records of 24 tunnel sections passing through graphitic, siliceous and micaceous phyllite as well as in schist and schistose mica gneiss of three different headrace tunnels of the hydropower project located in the Nepal Himalaya are exploited. The comprehensive tunnel monitoring records, rock mass quality records, laboratory testing results, topographic and geological information of the project areas are used as background material for the assessment.

\section{The Tunnel Cases}

Three headrace tunnel cases, which have undergone plastic deformation (tunnel wall convergence) during construction, have been selected for the detailed analysis of both timeindependent (instantaneous) and time-dependent (long-term) plastic deformations. These cases include headrace tunnels of Kaligandaki 'A' hydropower project, Middle Marsyangdi hydropower project and Khimti I hydropower project located in various part of the Nepal Himalaya. Figure 1 highlights both structural arrangements and geological conditions along the waterway system of all three hydropower projects.

\subsection{Kaligandaki Headrace Tunnel}

The 5950-m-long headrace tunnel of Kaligandaki 'A' hydropower project (KGA) is horseshoe shaped and has an excavated diameter of $8.3 \mathrm{~m}$ with a cross-sectional area of $58 \mathrm{~m}^{2}$. Most part of the headrace tunnel was excavated using drill and blast method with heading, benching and full-face excavation depending upon the quality of rock mass met while tunneling. The primary rock support applied during construction mainly consisted of steel ribs of ISMB 125 spaced at an interval ranging from 0.6 to $1.5 \mathrm{~m}$, steel fiber reinforced shotcrete having thickness ranging from 15 to $60 \mathrm{~cm}$ and 4-m-long $25-\mathrm{mm}$-diameter fully grouted rock bolts. The extent of rock support installed during construction varied considerably and depended on the rock mass quality condition met along the tunnel alignment. As final support, the headrace tunnel was fully concrete lined after the completion of tunnel excavation work.

Geologically, the project area is located in the Lesser Himalayan meta-sedimentary rock formations and is relatively close to the main boundary fault (MBT). As seen in Fig. 1a, the headrace tunnel passes through dolomite, weak and highly schistose graphitic and siliceous phyllites. The phyllitic rock mass along the tunnel is gray to dark gray, slightly to highly weathered, thinly foliated, and fractured to blocky with shear seams mostly parallel to the foliation joints (NEA 2002). The headrace tunnel passes through varying rock cover with highest rock cover of $620 \mathrm{~m}$ (Panthi and Nilsen 2007b). Significant length of the headrace tunnel (over 70\% length) passes through relatively high rock cover exceeding $300 \mathrm{~m}$ (Fig. 1a), which exhibits medium to high in situ gravitational stress. On the other hand, the schistose phyllite has relatively low strength and deformability properties. As a result, the headrace tunnel experienced moderate to high degree of plastic deformation along the periphery of the headrace tunnel contour. The systematically recorded tunnel wall displacement ranged from few centimeters to maximum up to $76 \mathrm{~cm}$ (Panthi 2006). In this analysis, the recorded longitudinal displacement (deformation) profiles of the tunnel sections having very poor to poor rock mass quality and stage of excavation were reviewed and selected in such a way that all selected tunnel sections consist records of both time-independent and total tunnel wall displacement. All together ten tunnel sections excavated in heading and six tunnel sections excavated in full face were selected (Shrestha 2014). The recorded longitudinal displacement for the heading excavations and full-face excavations is presented in Fig. 2a, b. It is noted here that the tunnel wall displacement record was in general started after the installation of rock support. Most of the deformation recordings were started within 2 days after the excavation and the tunnel face advanced between 0.8 and $4 \mathrm{~m}$ during that period depending upon the rock mass quality conditions met.

The rock mass is classified in different quality class using one or more rock mass classification system such as the rock mass rating (RMR) of Bieniawski $(1973,1989,1993)$, the Norwegian Q-system of Barton et al. (1974) and Grimstad and Barton (1993) and Geological Strength Index (GSI) of Hoek (1994). The overall quality of the rock mass in the selected tunnel sections varied considerably and ranged 


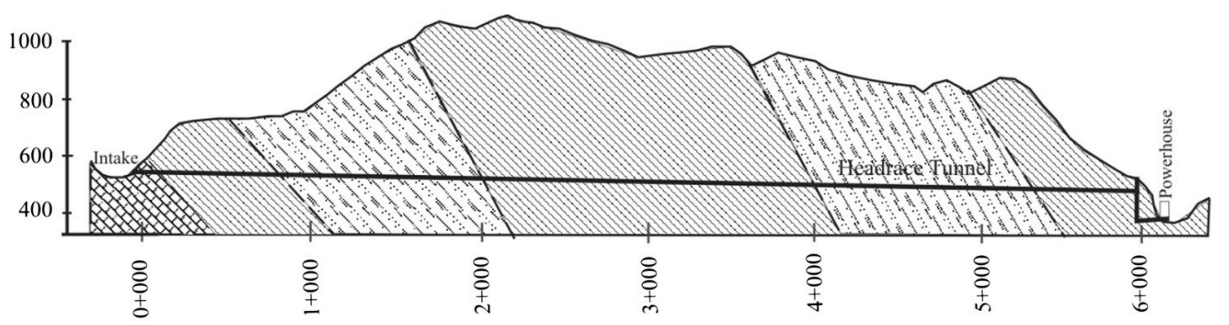

(a) Longitudinal Geological Profile of Kaligandaki Headrace Tunnel

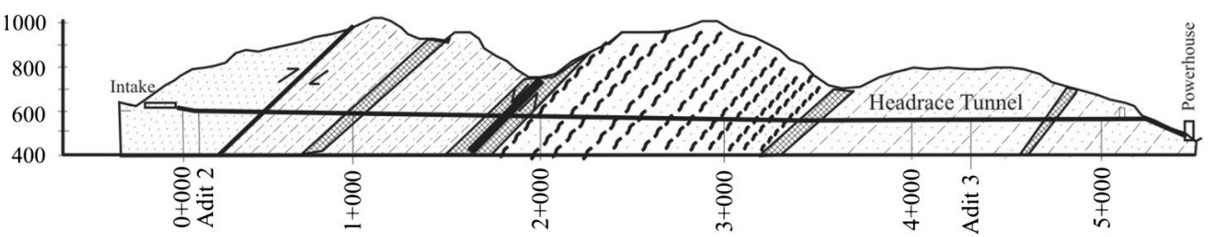

(b) Longitudinal Geological Profile of Middle Marsyangdi Headrace Tunnel

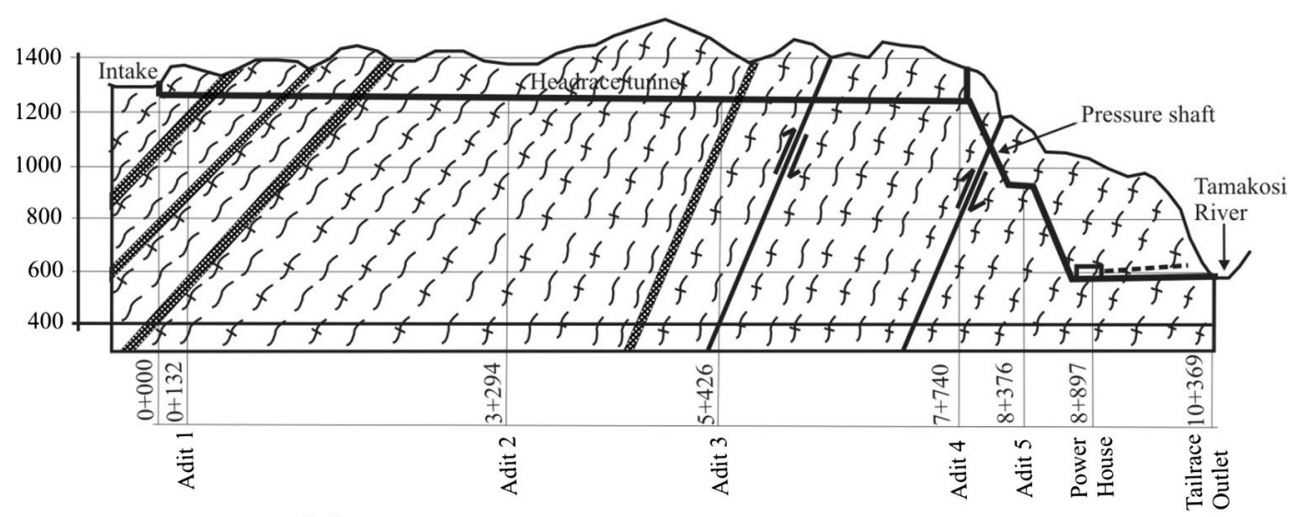

(c) Longitudinal Geological Profile of Khimti Headrace Tunnel

Legends

$\begin{array}{lll}\text { Siliceous dolomite } & \square \text { Quartzite } & \text { Mica gneiss and mica schist intercalation } \\ \text { Siliceous phyllite } & \text { Quartzite and phyllite intercalation } & \text { W }\end{array}$

Fig. 1 Structural arrangement and geological conditions along the waterway system of three headrace tunnel cases

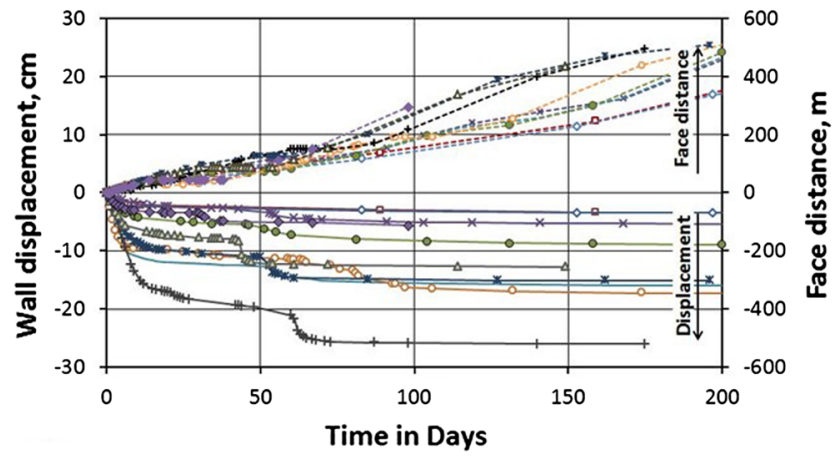

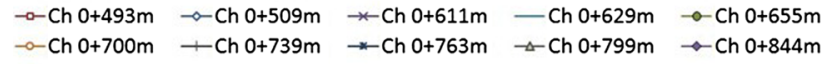

(a) Kaligandaki tunnel - heading sections

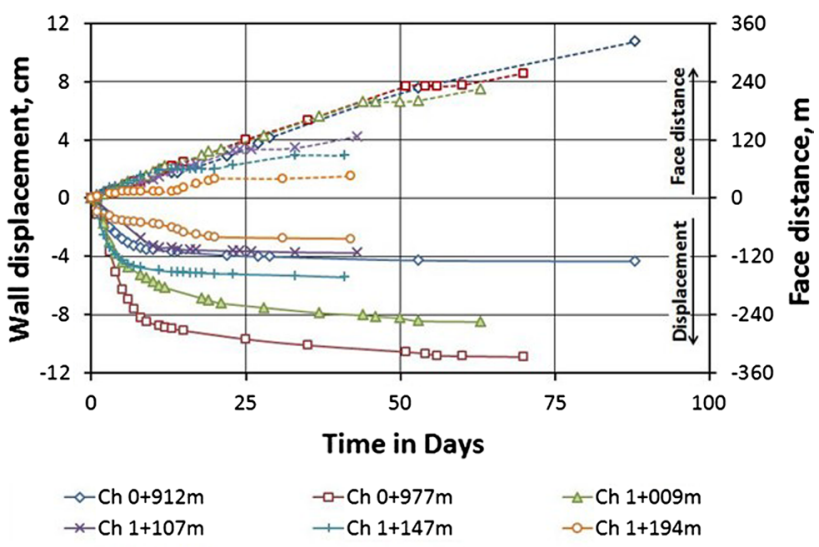

(b) Kaligandaki tunnel - fullface sections

Fig. 2 Horizontal displacement with respect to time and face distance of the selected sections of Kaligandaki headrace tunnel (Shrestha 2014) 
from extremely poor to poor category rock mass according to Q-system. The detailed description of the rock mass condition in each of these selected tunnel sections is presented in Table 1.

\subsection{Middle Marsyangdi Headrace Tunnel}

The 5300-m-long headrace tunnel of Middle Marsyangdi Hydropower Project (MMHEP) is also horseshoe shaped and has an excavation diameter of $6.4 \mathrm{~m}$ with $34 \mathrm{~m}^{2}$ cross-section area. The tunnel was excavated full face using drill and blast method. The preliminary rock support applied along the headrace tunnel consisted of plain or steel fiber reinforced shotcrete together with or without wire mesh, rock bolts and steel ribs. Wire mesh was normally used in the faulted rock mass, whereas cement grouted rock bolts were installed systematically along the whole headrace tunnel alignment. Steel ribs were used in tunnel stretches where rock mass was of exceptionally poor to very poor quality. Normally, the spacing of steel ribs varied from 1 to $1.7 \mathrm{~m}$ apart from the tunnel sections passing through faulted rock mass where the steel ribs were installed as close as $0.2 \mathrm{~m}$ spacing (NEA 2011). After the completion of tunnel excavation, the headrace tunnel was fully concrete lined as permanent support.
Geologically, this project is also located in the lesser Himalayan meta-sedimentary rock formation and the headrace tunnel passes through rock formation consisting of quartzite, meta-sandstone and phyllite intercalation. The upstream part of the tunnel (approximately $400 \mathrm{~m}$ ) passes through fractured and foliated quartzite. The rest of the headrace tunnel passes through either siliceous phyllite or micaceous phyllite in intercalation with meta-sandstones (Fig. 1b).

In order to monitor tunnel behavior during excavation, extensive deformation measurements were taken at various sections of the headrace tunnel. The extent of tunnel wall deformation varied from couple of centimeters to as high as $17 \mathrm{~cm}$ (Panthi 2006). Based on the deformation pattern, rock mass quality and detailed instrumentation condition, six representative headrace tunnel sections were selected from MMHEP headrace tunnel for the analysis (Shrestha 2014). The tunnel wall displacement pattern with respect to face distance is presented in Fig. 3a. The measurement of tunnel wall displacement was started immediately after the rock support installation and after the tunnel faces advanced by approximately $1.5-3.4 \mathrm{~m}$.

Overall rock mass quality along the selected tunnel sections varied from very poor to extremely poor quality. The

Table 1 Rock mass quality conditions of the tunnel sections at Kaligandaki headrace tunnel (from NEA 2002)

Tunnel Chainage (m) Rock type and rock mass conditions Quality class as Average $Q$-value per Q-system

Ch. $0+493$
Ch. $0+509$
Ch. $0+611$
Ch. $0+629$
Ch. $0+655$
Ch. $0+700$
Ch. $0+739$
Ch. $0+763$
Ch. $0+799$
Ch. $0+844$
Ch. $0+912$
Ch. $0+977$
Ch. $1+009$
Ch. $1+107$
Ch. $1+147$
Ch. $1+194$

Fractured and very weak graphitic phyllite with quartz veins and occasional local faulting

Fractured and weak graphitic phyllite with numerous quartz veins

Fractured and weak graphitic phyllite with quartz veins and numerous small-scale shear zones with microfolding

Fractured and very weak graphitic phyllite with quartz veins and a shear seam filled with 3-cm-thick clay at the right wall

Fractured and very weak graphitic phyllite with quartz veins and numerous folded shear zones

Fractured and very weak graphitic phyllite with a local fault filled with $10-30 \mathrm{~cm}$ clay gouge

Fractured and faulted very weak graphitic phyllite with the presence of quartz veins Fractured and faulted very weak graphitic phyllite with the presence of quartz veins Fractured and faulted very weak graphitic phyllite with the presence of quartz veins Fractured and very weak graphitic phyllite with quartz veins and numerous microfolded shear zones

Fine-grained, jointed, weak to medium-strong siliceous phyllite with quartz veins

Fine-grained, jointed, medium-strong siliceous phyllite with quartz veins

Fine-grained, jointed, medium-strong siliceous phyllite with quartz veins

Fine-grained, jointed, medium-strong siliceous phyllite with quartz veins

Fine-grained, jointed, weak to medium-strong siliceous phyllite with quartz veins and numerous shear planes with thin clay filling

Fine-grained, jointed, weak siliceous phyllite with quartz veins and numerous shear planes with thin clay filling
Extremely poor 0.065

Very poor $\quad 0.375$

Very poor $\quad 0.300$

Extremely poor $\quad 0.070$

Extremely poor $\quad 0.03$

Extremely poor 0.03

Extremely poor $\quad 0.02$

Extremely poor 0.02

Extremely poor 0.02

Extremely poor 0.025

Very poor $\quad 0.66$

Poor $\quad 1.33$

Poor $\quad 1.33$

Poor $\quad 2.00$

Poor $\quad 2.00$

Poor $\quad 1.78$ 


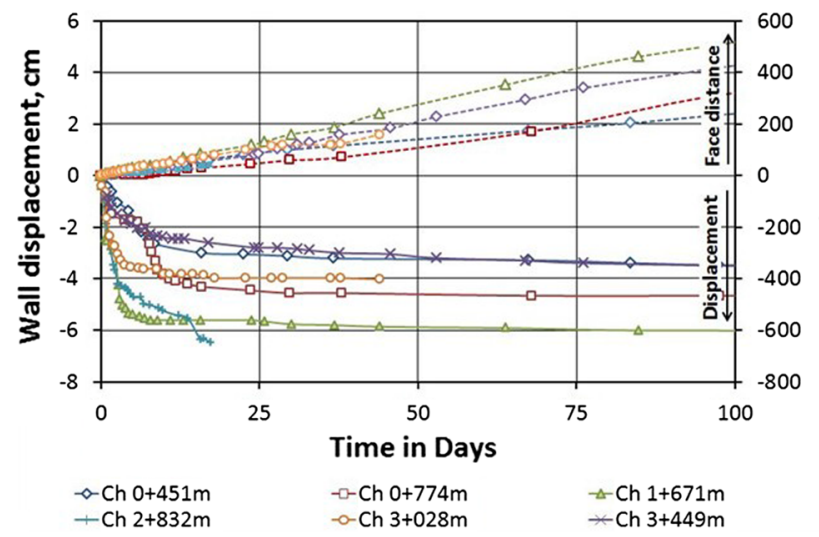

(a) Middle Marsyangdi tunnel sections

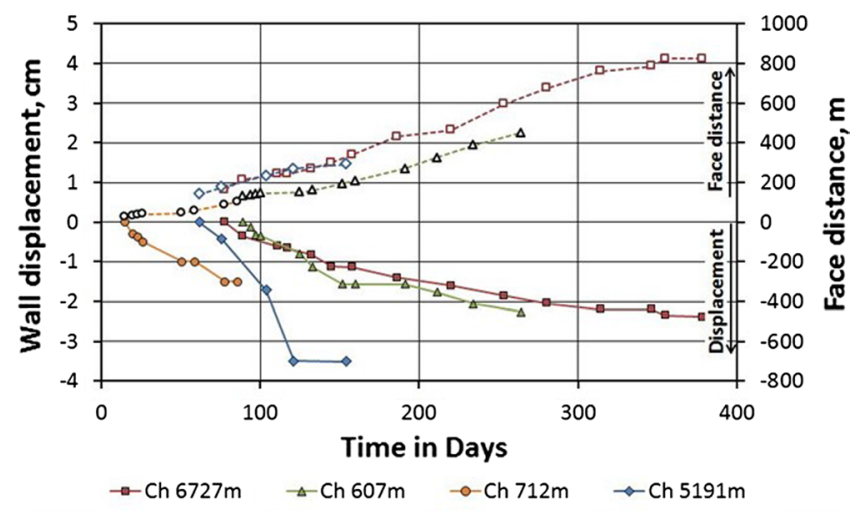

(b) Khimti tunnel sections

Fig. 3 Horizontal displacement with respect to time and face distance in a Middle Marsyangdi and $\mathbf{b}$ Khimti headrace tunnel sections (Shrestha 2014)

details about the rock type and rock mass quality descriptions are presented in Table 2.

\subsection{Khimti Headrace Tunnel}

The 7889-m-long headrace tunnel of Khimti I hydropower project (KHP) is inverted-D shaped and has an excavation diameter varying from 4 to $4.3 \mathrm{~m}$ with the cross-sectional area varying from 11 to $14 \mathrm{~m}^{2}$. The project area is bounded by one of the major faulting system of the Himalaya called Main Central Thrust (MCT). The main rock types in the project area are mica gneiss, banded gneiss, and granitic gneiss in intercalation with sheared chlorite and talcose mica schist (Fig. 1c). The tunnel was excavated full face using drill and blast method and supported mostly by steel fiber shotcrete, cement grouted rock bolts. Spiling bolts were used occasionally in the tunnel sections where extremely weak rock mass encountered (Panthi and Nilsen 2007a). Deformation in some tunnel sections was noticed much later after many days of excavation and was recorded systematically. The most pronounced four such tunnel sections where long-term deformation was recorded are presented in Fig. 3b. First measurement of tunnel deformation was done when the tunnel face reached ahead by $131 \mathrm{~m}$ at Chainage $0+607 \mathrm{~m}, 26 \mathrm{~m}$ at Chainage $0+712 \mathrm{~m}, 142 \mathrm{~m}$ at Chainage $5+191 \mathrm{~m}$ and $164 \mathrm{~m}$ at $\mathrm{Ch} 6+727 \mathrm{~m}$. The deformation measurement was started after 15-89 days after tunnel excavation. Hence, the records presented for Khimti headrace tunnel sections shown in Fig. 3 mainly represent time-dependent tunnel deformations. The extent of possible total deformation including both instantaneous and time-dependent deformations was extensively analyzed by Shrestha and Panthi (2014a).

Overall rock mass quality in the selected tunnel sections varied from extremely to exceptionally poor rock mass class according to Q-system. The rock type and rock mass quality description of selected four tunnel sections are presented in Table 3.

Table 2 Rock mass quality conditions of the selected tunnel sections at MMHEP headrace tunnel (from NEA 2011)

\begin{tabular}{|c|c|c|c|}
\hline Tunnel Chainage (m) & Rock type and rock mass conditions & $\begin{array}{l}\text { Quality class as } \\
\text { per Q-system }\end{array}$ & $\begin{array}{l}\text { Average } \\
Q \text {-value }\end{array}$ \\
\hline Ch. $0+451$ & $\begin{array}{l}\text { Fractured and sheared phyllite and schistose quartzite intercalation. Sheared bands of phyllite } \\
\text { are present where clay gouge filling exists }\end{array}$ & Very poor & 0.46 \\
\hline Ch. $0+774$ & $\begin{array}{l}\text { Siliceous phyllitic and schistose quartzite intercalation. Rock mass is weak, fractured, } \\
\text { sheared and schistose consisting microfolded shear bands and lenses of quartz veins within } \\
\text { phyllite }\end{array}$ & Extremely poor & 0.05 \\
\hline Ch. $1+617$ & $\begin{array}{l}\text { Siliceous phyllite and schistose quartzite intercalation. Highly fractured, sheared and schis- } \\
\text { tose rock mass representing weakness zone }\end{array}$ & Extremely poor & 0.03 \\
\hline Ch. $2+832$ & Schistose (micaceous) and sheared phyllite and meta-sandstone intercalation & Very poor & 0.14 \\
\hline Ch. $3+028$ & Schistose (micaceous) phyllite and meta-sandstone intercalation & Very poor & 0.46 \\
\hline Ch. $3+449$ & Schistose (micaceous) and sheared phyllite and meta-sandstone intercalation & Very poor & 0.18 \\
\hline
\end{tabular}


Table 3 Rock mass quality description of the selected tunnel sections at Khimti headrace tunnel

\begin{tabular}{llll}
\hline Tunnel Chainage $(\mathrm{m})$ & Rock type and rock mass conditions & Quality class as per Q-system & Average $Q$-value \\
\hline Ch. $0+607$ & $\begin{array}{l}\text { Highly deformed mica schist and mica gneiss intercalation. Very } \\
\text { weak, faulted sheared rock mass }\end{array}$ & Exceptionally poor & 0.005 \\
Ch. $0+712$ & $\begin{array}{l}\text { Highly deformed mica schist and mica gneiss intercalation. Highly } \\
\text { sheared and faulted rock mass }\end{array}$ & Exceptionally poor & 0.002 \\
Ch. $5+191$ & Bands of highly deformed mica schist intercalation within mica gneiss & Extremely poor & 0.02 \\
Ch. $6+272$ & Highly deformed, sheared and extremely poor mica schist & Exceptionally poor & 0.002 \\
\hline
\end{tabular}

\section{Rock Mass Properties and In Situ Stresses}

At first the rock mass strength of the studied tunnel sections was back calculated using Hoek and Marinos (2000) approach on tunnel squeezing. The rock support pressure recorded at the Kaligandaki headrace tunnel ranged from 0.6 to $1.0 \mathrm{MPa}$ and at the Middle Marsyangdi headrace tunnel from 0.6 to $1.6 \mathrm{MPa}$. The recorded support pressure values were found to be very similar as were estimated by Panthi and Nilsen (2007b). The Poison's ratio $(\nu)$ was taken 0.1 based on the laboratory testing carried out by Panthi (2006) for the phyllite rock samples collected from both tunnels, $m_{i}$ value was estimated $7-14$, and modular ratio (MR) was estimated between 463 and 550 on the basis of the rock type (Hoek 2007). The back calculated intact rock strength $\left(\sigma_{\mathrm{ci}}\right)$ ranged from 14 to $40 \mathrm{MPa}$ for Kaligandaki headrace tunnel sections and 17-43 MPa for Middle Marsyangdi headrace tunnel sections. The estimated intact rock strength values were compared with the laboratory tested results presented in Panthi (2006) and found to be in line with tested intact rock strength values for graphitic, siliceous and micaceous phyllites. The rock mass properties of the Khimti tunnel sections were directly taken for the estimates presented by Shrestha and Panthi (2014a). Table 4 highlights rock types, overall rock mass quality described by Q-system and respective records of GSI values, estimated rock mass strength $\left(\sigma_{\mathrm{cm}}\right)$, rock mass shear modulus $(G)$ and in situ stress conditions for all selected tunnel sections.

Overburden at the selected tunnel section of the Kaligandaki varies from 230 to $345 \mathrm{~m}$, which gives vertical gravitational stress magnitude ranging from 6.2 to $9.3 \mathrm{MPa}$. Similarly, the overburden of the selected tunnel sections of the Middle Marsyangdi varies from 320 to $455 \mathrm{~m}$, which gives vertical gravitational stress magnitude ranging from 8.48 to $12.06 \mathrm{MPa}$. The tectonic component of the horizontal stress for Kaligandaki and Khimti headrace tunnels was taken as $3 \mathrm{MPa}$ based on in situ data measurement records summarized by Nepal (1999) and evaluated by Shrestha and Panthi (2014a, b, respectively). Similarly, the tectonic component of the horizontal stress for Middle Marsyangdi headrace tunnel was estimated to be $3.5 \mathrm{MPa}$ using the base data of the stress measurement presented by Nepal (1999).
Since the tectonic stress in the middle part of the Himalaya is oriented close to north-south (Panthi 2012), the tectonic stress components across the selected tunnel sections were adjusted (resolved) according to the orientation of the tunnel alignments. The headrace tunnels of Kaligandaki and Middle Marsyangdi have trends of $144-324^{\circ}$ and $160-340^{\circ}$, respectively. Similarly, upstream and downstream parts of the Khimti headrace tunnel have trends of $10-190^{\circ}$ to $60-240^{\circ}$, respectively. It is noted here that the total horizontal stress component is the sum of resolved tectonic stress and gravity led horizontal stress. The computed vertical stresses $\left(\sigma_{\mathrm{v}}\right)$, resolved in-plane horizontal stress $\left(\sigma_{\mathrm{h}}\right)$ and ratio of horizontal to vertical stress $(k)$ at the studied tunnel sections are also presented in Table 4.

Lower values of the stress ratio in Table 4 show high degree of in situ stress anisotropy in most of the tunnel sections. As a result, deformations in tunnel contour varied considerably depending upon the rock mass stiffness (deformability) and degree of in situ stress anisotropy. According to Fairhurst and Carranza-Torres (2002), the point of maximum deformation is on the tunnel contour parallel to the direction of the maximum principal stress direction and minimum on the tunnel contour perpendicular to the direction of the maximum principal stress. In the inverted-D-shaped headrace tunnels of Kaligandaki, Middle Marsyangdi and Khimti where horizontal stress magnitude is considerably less as compared to the vertical stress (Table 4), the recorded deformations were therefore higher in the tunnel walls than in the tunnel roof.

\section{Plastic Deformation Over Time}

Tunnel deformation in general can be categorized into timeindependent and time-dependent deformations. Time-independent deformation normally occurs during and immediately after the tunnel excavation. As the tunnel face acts as a column giving 'fictitious' support, it is quite obvious to assume that the time-independent deformation increases as the tunnel face advances ahead from the measurement station. Normally, the time-independent deformation reaches its maximum value as the tunnel face has advanced by more 


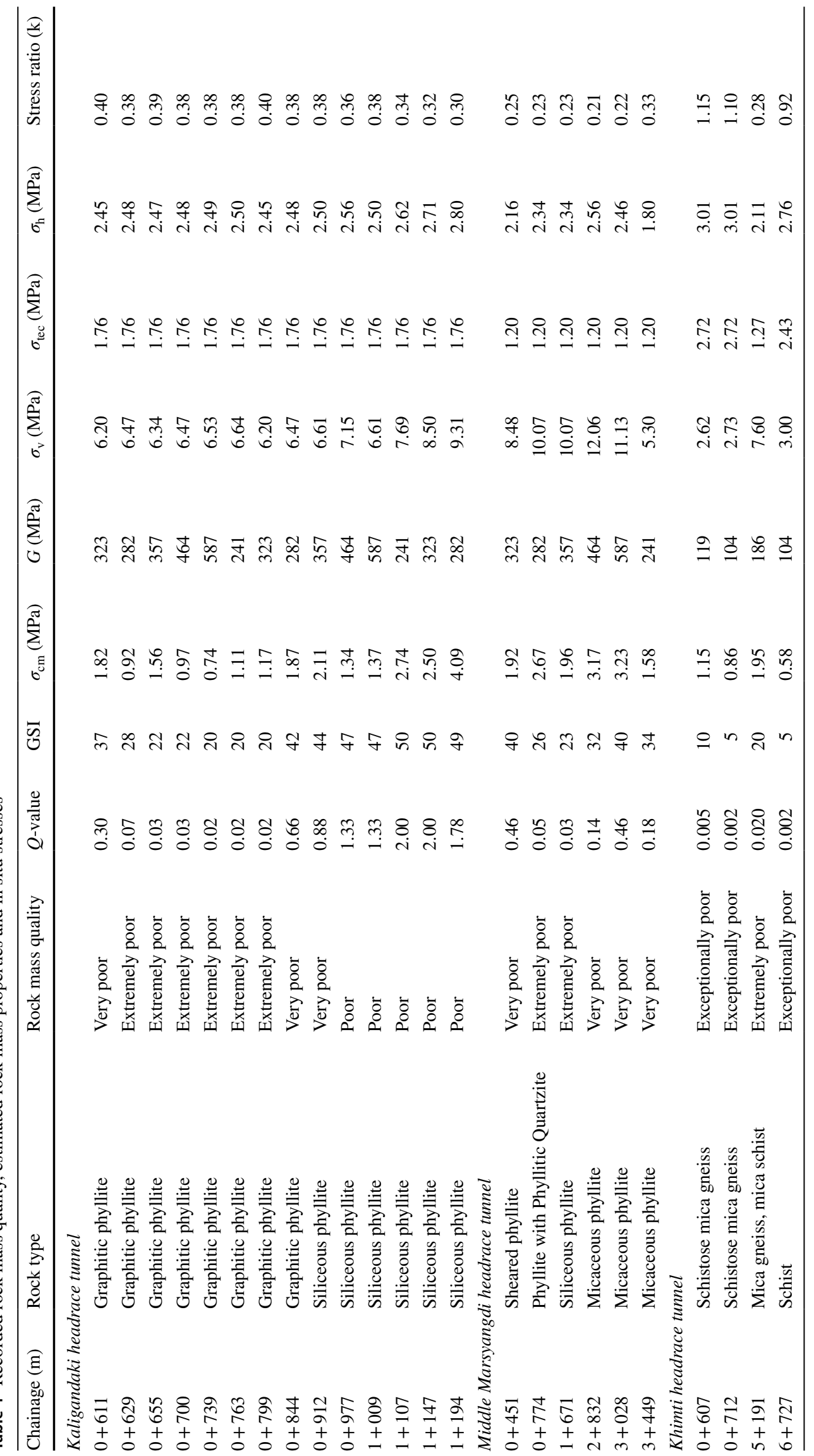


than four times the tunnel diameter (Carranza-Torres and Fairhurst 2000). However, there are exceptions to this understanding such as highlighted by Vlachopoulos et al. (2009). The tunnel deformation records presented in Figs. 2 and 3 clearly show a continuing increment of deformations even after the tunnel face effect practically ceased, which suggests a time-dependent deformation related to the long-term creep.

Such time-independent and time-dependent deformations can be distinguished from the total deformation records collected during long-term periodic measurements. The curve fitting model proposed by Sulem et al. (1987a, b) expressed by (Eq. 1) is a useful way to distinguish this phenomenon. Equation (1) can be divided into two components representing both time-independent $\left(C_{(x)}\right)$ and time-dependent $\left(C_{(t)}\right)$ displacements represented by Eqs. (2) and (3), respectively.

$C(x, t)=C_{\infty x}\left[1-\left(\frac{X}{x+X}\right)^{2}\right]\left[1+m\left\{1-\left(\frac{T}{t+T}\right)^{n}\right\}\right]$

$C_{(x)}=C_{\infty x}\left[1-\left(\frac{X}{x+X}\right)^{2}\right]$

$C_{(t)}=C_{\infty x x} m\left[1-\left(\frac{X}{x+X}\right)^{2}\right]\left[1-\left(\frac{T}{t+T}\right)^{n}\right]$

Here, $C_{(x, t)}$ is convergence (deformation) in tunnel at distance $x$ from tunnel face at $t$ days of tunnel excavation, $C_{\infty x x}$ is instantaneous tunnel closure obtained in the case of an infinite rate of face advance without having effect of timedependent deformation, $X$ is a length related to the distance of influence of the tunnel face, $m$ represents increment of instantaneous deformation due to effect of rheology, $T$ is a characteristic parameter of the time-dependent properties of the ground, and $n$ is a constant normally taken as 0.3 as suggested by Sulem et al. $(1987 \mathrm{a}, \mathrm{b}) . C_{(x)}$ that relates to $C_{\infty x}, x$ and $X$ describes the deformation in tunnel as tunnel face advances and is termed as the time-independent deformation, whereas $C_{(t)}$ relates to $T, t$ and $n$ representing a multiplier of $C_{\infty x}$ and $m$ and is termed as the time-dependent deformation. Once the tunnel face advances far away from the measurement station such that distance $x$ and time $t$ are virtually infinite, the final closure (FC) in tunnel can be computed as $C_{\infty x}(l+m)$.

In order to determine the time-independent and timedependent components out of the total measured deformation in the studied tunnel sections, the parameters $C_{\infty \propto x}, X, T$ and $m$ were fitted in Eq. (1) in such a way that sum of square of errors between measured and computed deformations is minimum. For this purpose, several hundreds of set of these parameters were randomly generated in a spreadsheet and the best set was chosen according to the least sum of square of errors. The measured and computed deformation charts of the Kaligandaki headrace tunnel sections (both heading and full-face excavation sections) and Middle Marsyangdi headrace tunnel sections are presented in Figs. 4, 5 and 6, respectively. Similar analysis approach was also used at the Khimti headrace tunnel sections by Shrestha and Panthi (2014a), and measured and computed deformation charts are presented in Fig. 7. Respective $C_{\infty x}, X, T$ and $m$ parameters including average error between measured and computed deformations and sum of squares of errors of each of the tunnel sections are presented in Table 5. Figures 4, 5, 6 and 7 show that there exists a goodness of fit between computed and measured deformations in the respective tunnel sections (Shrestha 2014).

It is important to know requirement of support pressure prior and during construction stages to avoid tunnel collapse. The first prerequisite for this is to know required preliminary support pressure, which can be related to the instantaneous deformation $\left(C_{\infty x}\right)$ in the tunnel periphery. In the meantime, it is also important that if potential total tunnel deformation (final closure FC) is known, then the final support requirement can also be estimated. The authors believe that the ratio of total deformation (FC) and instantaneous deformation $\left(C_{\infty x x}\right)$ should be a good reference for estimating additional support requirement on top of the initially applied support. Considering this fact, instantaneous and time-dependent variables described by Eqs. (1-3) were computed and are presented in Table 5. The calculated average value of $\mathrm{FC} / C_{\infty x}$ is 1.90 and 2.0 at the heading and full-face excavated tunnels sections of Kaligandaki, respectively. Similarly, the average value of $\mathrm{FC} / C_{\infty x}$ is 1.70 at the tunnel sections of Middle Marsyangdi and 1.92 based on the three tunnel sections for Khimti (excluding exceptional value of 5.8), respectively.

\section{Influence of Stress Anisotropy on Deformation}

In general, the extent of deformation in tunnel can be related to rock mass deformability properties, support pressure and in situ stresses. For a circular tunnel at an isostatic stress condition, Carranza-Torres and Fairhurst (2000) suggested that the deformation may be assessed through convergence confinement method by constructing a ground reaction curve, graphical response of the rock mass deformation against support pressure. Similarly, for the same tunnel, Hoek and Marinos (2000) suggested a link between tunnel strain (a ratio between tunnel deformation and tunnel diameter multiplied by hundred), and the ratio between rock mass strength and vertical gravitational stress. However, it is seldom that the in situ stress is isostatic. In this respect, an attempt was made to establish a link between tunnel strain (for both instantaneous and total tunnel strain), vertical gravitational stress $\left(\sigma_{v}\right)$, horizontal to vertical stress 


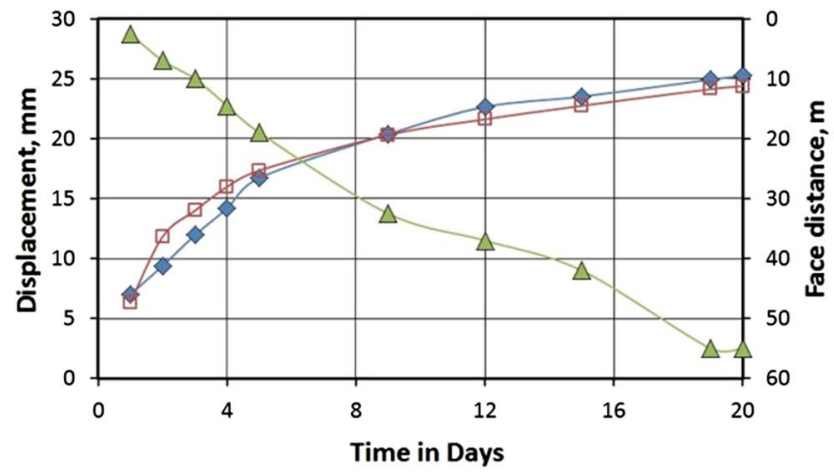

(a) Chainage $0+611 \mathrm{~m}$

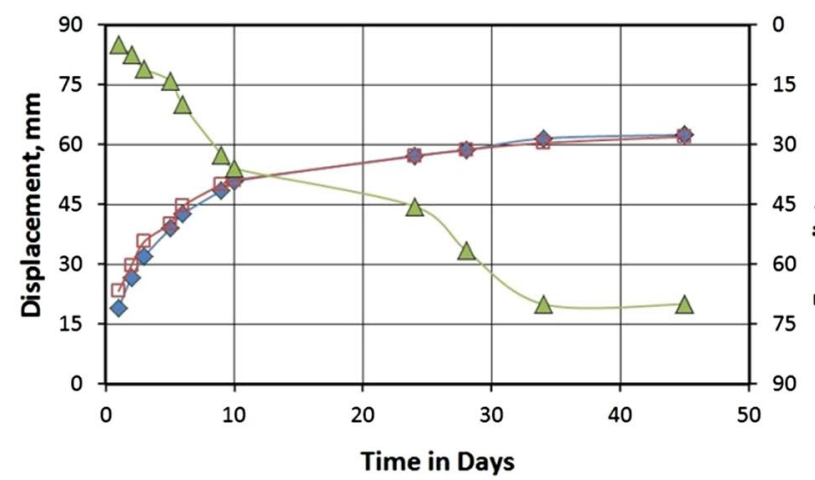

(c) Chainage $0+655 \mathrm{~m}$

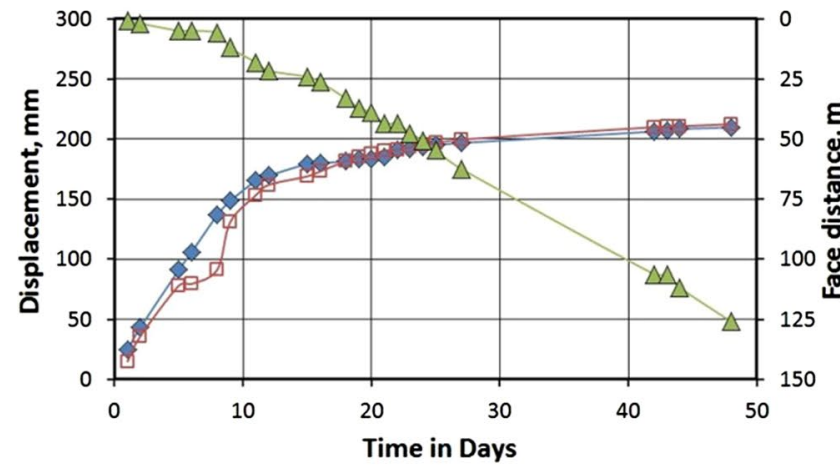

(e) Chainage $0+739 \mathrm{~m}$

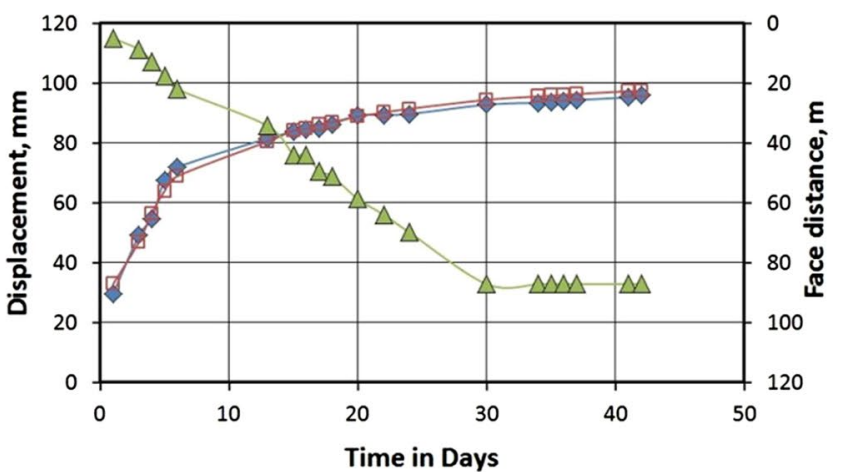

(g) Chainage $0+799 \mathrm{~m}$

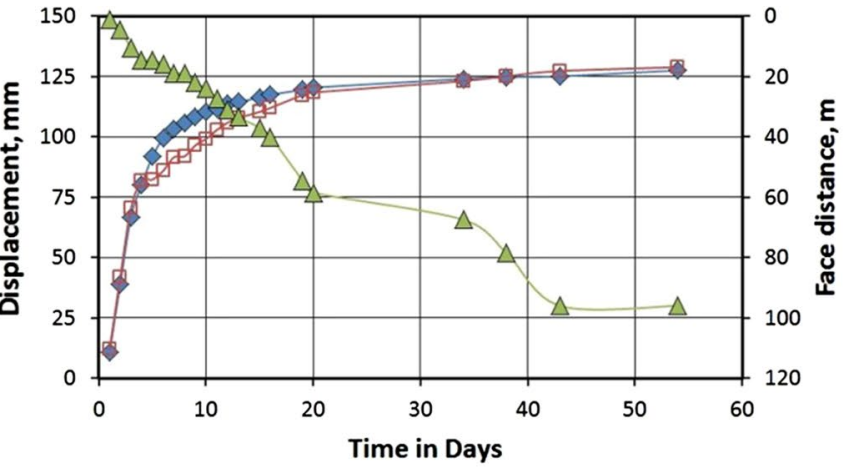

(b) Chainage $0+629 \mathrm{~m}$

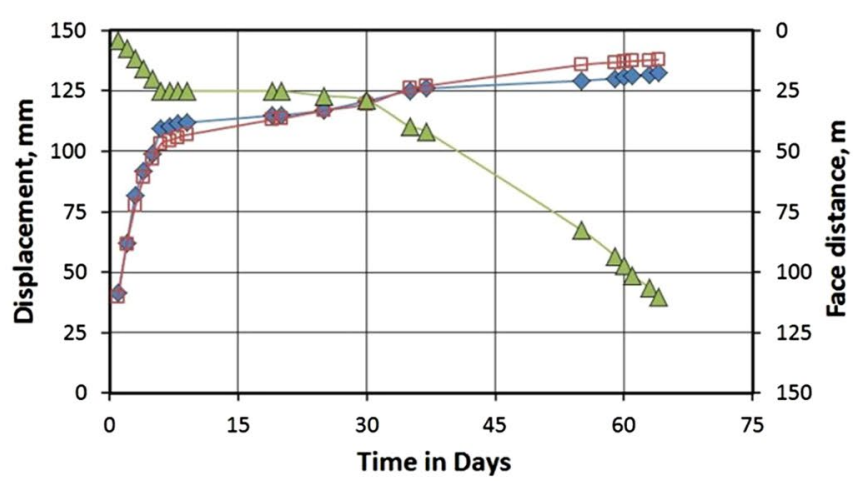

(d) Chainage $0+700 \mathrm{~m}$

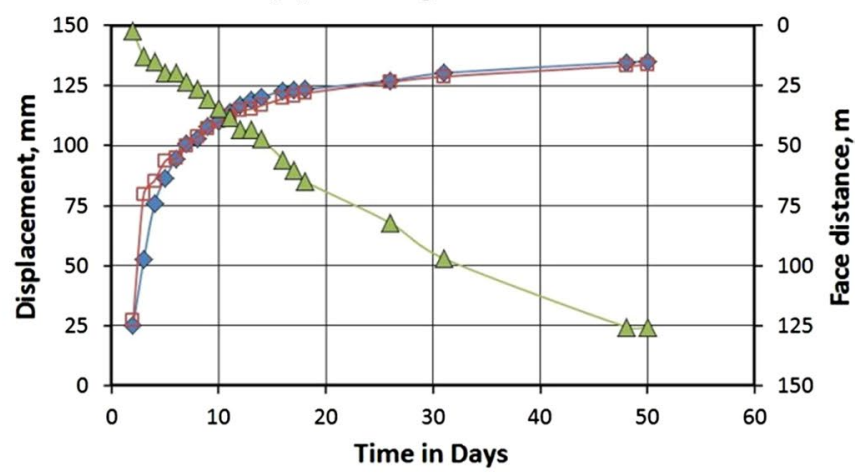

(f) Chainage $0+763 \mathrm{~m}$

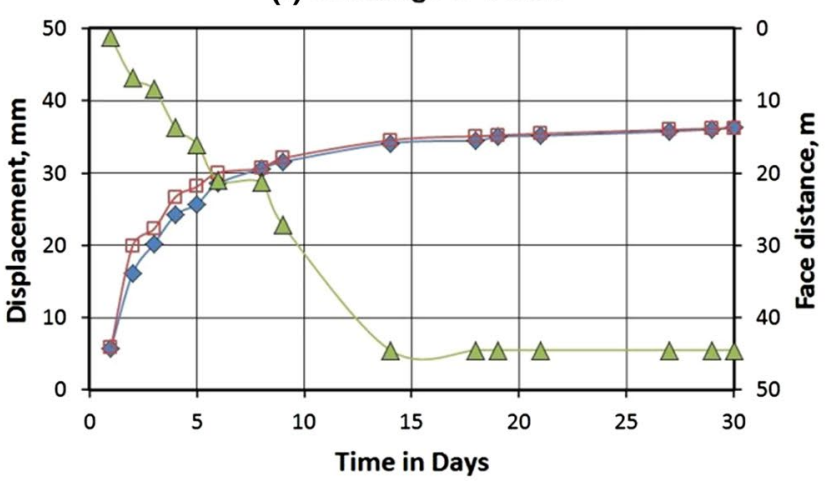

(h) Chainage $0+844 \mathrm{~m}$

$\sim$ Measured displacement $\quad \boxminus$ Computed displacement $\quad \triangle$ tunnel advance

Fig. 4 Computed and actually measured deformation in the KGA heading tunnel sections (Shrestha 2014) 


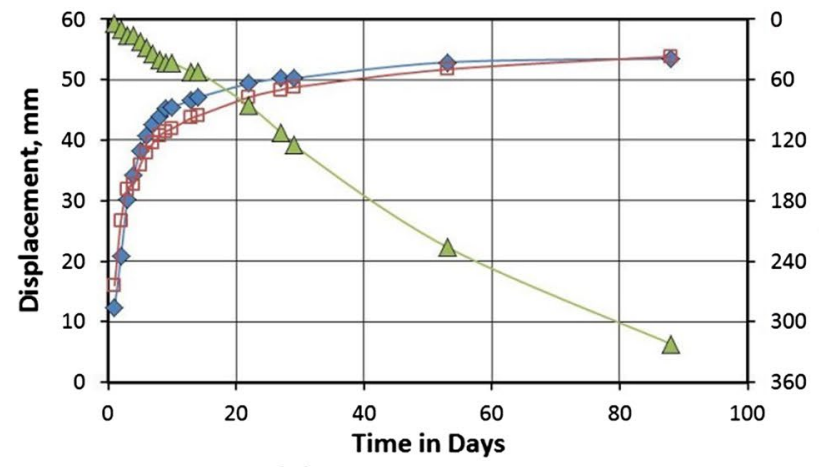

(a) Chainage $0+912 \mathrm{~m}$

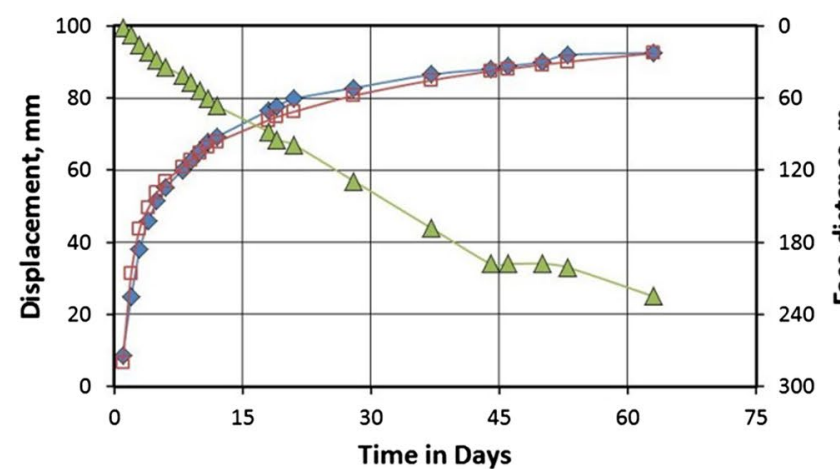

(c) Chainage $1+009 \mathrm{~m}$

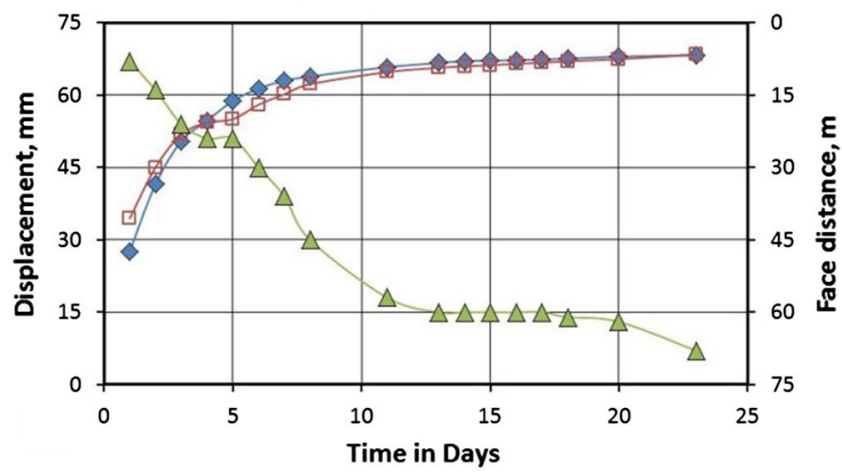

(e) Chainage $1+147 \mathrm{~m}$

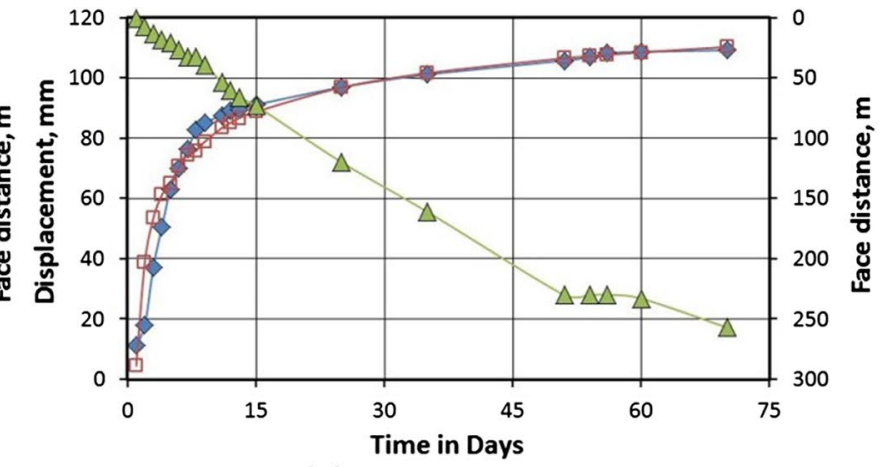

(b) Chainage $0+977 \mathrm{~m}$

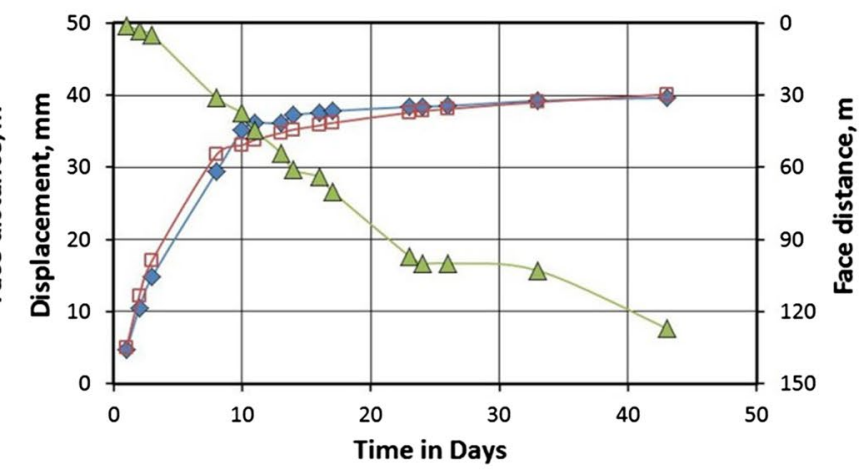

(d) Chainage $1+107 \mathrm{~m}$

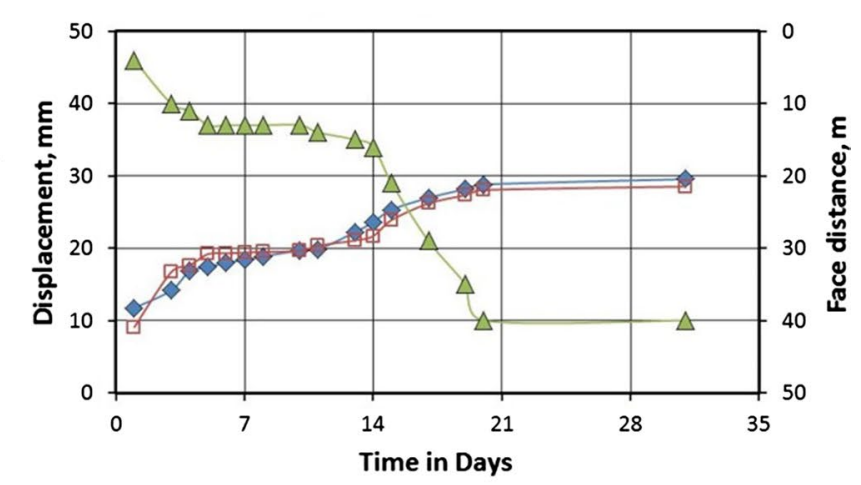

(f) Chainage $1+194 \mathrm{~m}$

$\triangle$ tunnel advance

Fig. 5 Computed and actually measured deformations in the KGA full-face tunnel sections (Shrestha 2014)

ratio $(k)$, support pressure $\left(p_{i}\right)$ and rock mass deformability properties expressed by shear modulus $(G)$ using the data information presented in Tables 4 and 5. Figure 8 is the outcome of this analysis, which clearly depicts that there exists fairly good link between tunnel strain and rock mass shear modulus $(G)$, support pressure $\left(p_{i}\right)$, vertical stress $\left(\sigma_{v}\right)$, horizontal to vertical stress ratio $(k)$. As can be seen in Fig. 8, the instantaneous closure $\left(C_{\infty x}\right)$ and final closure $(\mathrm{FC})$ values are indirectly proportional to the rock mass shear modulus and support pressure values and directly proportional to the in situ stress conditions, which is in fact very logical. This is because weaker the rock mass, more will be the deformation magnitude; less stiff the applied support, more will be the deformation magnitude; and higher the stress magnitude, higher will be the deformation magnitude.

Using the trend line expressed in Fig. 8 (Shrestha 2014), Eqs. (4) and (5) are proposed to calculate the instantaneous and final tunnel strain. The strength of the proposed equations is that these are capable of addressing the stress anisotropy, which is the reality in most of the tunnels cases. It is once again repeated here that none of the presently practiced approaches incorporate stress anisotropy in assessing plastic deformation in tunnels. In addition, the authors argue that the shear modulus of the rock mass, gravity stress, stress 


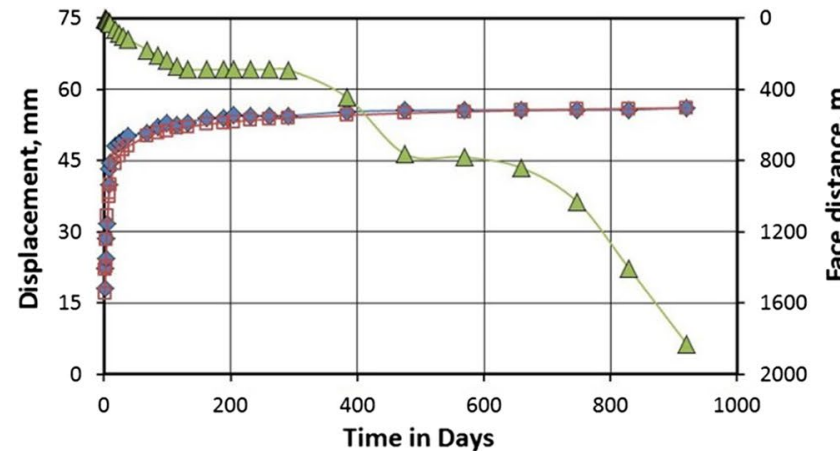

(a) Chainage $0+451 \mathrm{~m}$

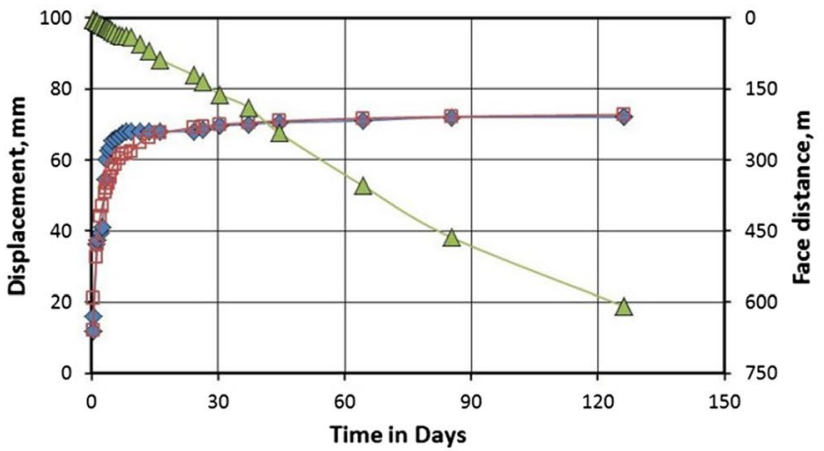

(c) Chainage $1+671 \mathrm{~m}$

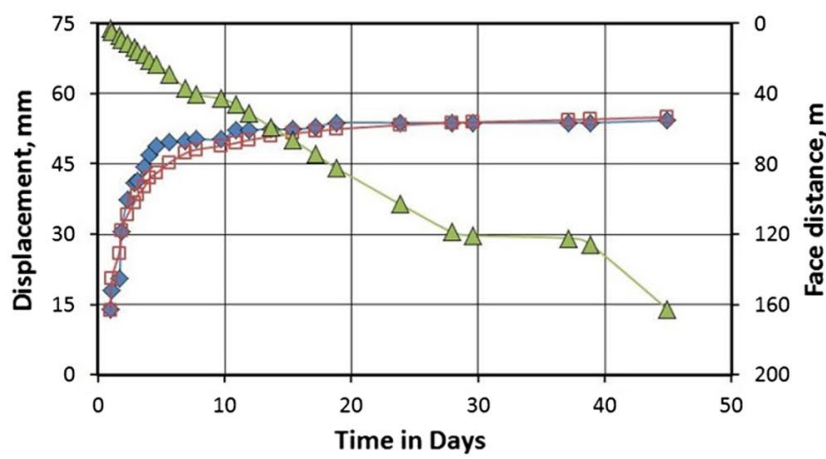

(d) Chainage $2+832 \mathrm{~m}$

$\neg$ Measured displacement

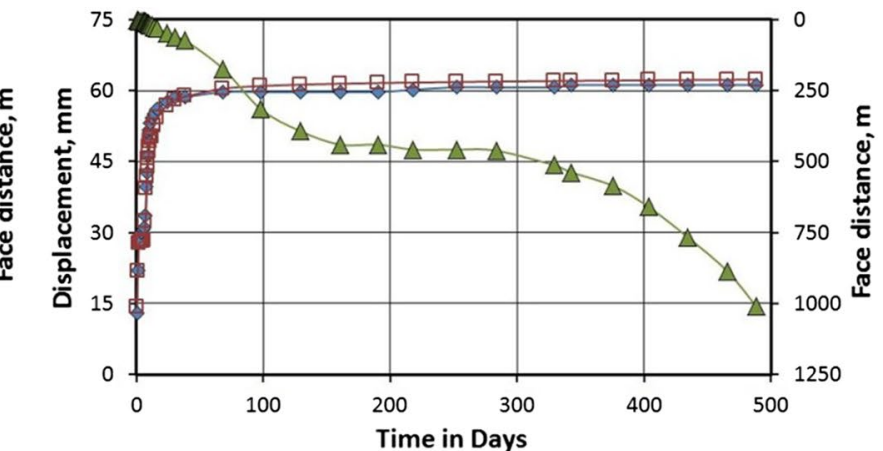

(b) Chainage $0+774 \mathrm{~m}$

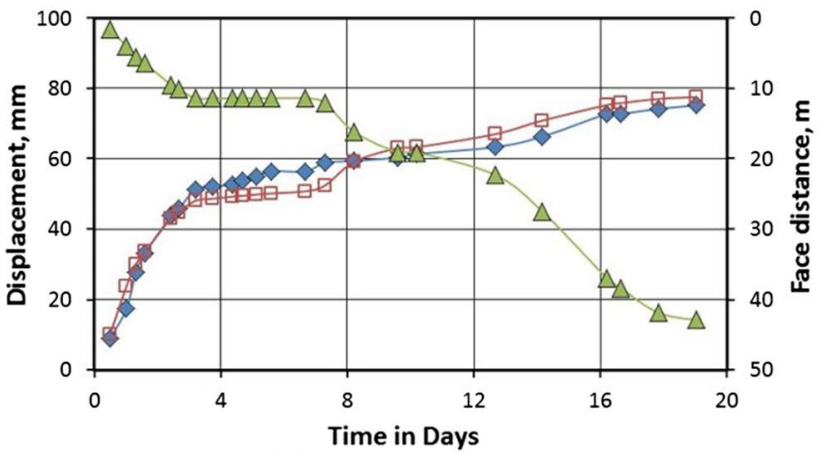

(e) Chainage $3+028 \mathrm{~m}$

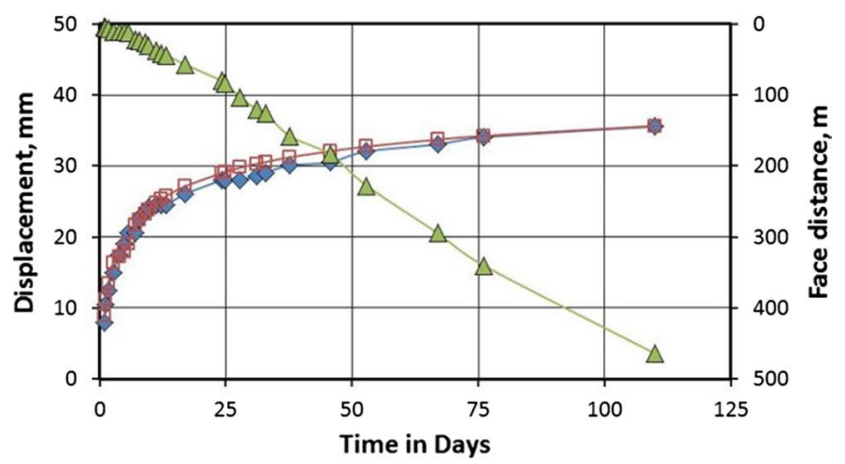

(f) Chainage $3+449 \mathrm{~m}$

$\triangle$ tunnel advance

Fig. 6 Computed and actually measured deformations in the MMHEP tunnel sections (Shrestha, 2014)

ratio and support pressures are directly linked to the extent of plastic deformation in tunnels.

$\varepsilon_{\mathrm{IC}}=3065\left(\frac{\sigma_{v}(1+k) / 2}{2 G\left(1+p_{i}\right)}\right)^{2.13}$

$\varepsilon_{\mathrm{FC}}=4509\left(\frac{\sigma_{v}(1+k) / 2}{2 G\left(1+p_{i}\right)}\right)^{2.09}$

Further analysis was conducted using Eqs. (4) and (5) to develop a simplified chart, which incorporates ratio of rock mass shear modulus and in situ stress condition (ranged from 50 to 500) for different support pressures (Fig. 9). This chart can be a useful tool in estimating required support pressure $\left(p_{i}\right)$ if rock mass shear modulus $(G)$, vertical stress $\left(\sigma_{v}\right)$ and horizontal to vertical stress ratio $(k)$ are known (Shrestha 2014).

It is a well known fact that there is a direct link between the rock mass shear modulus $(G)$ and rock mass deformation modulus $\left(E_{\mathrm{rm}}\right)$ as expressed by Eq. (6) suggested by Carranza-Torres and Fairhurst (2000). Similarly, the rock mass deformation modulus $\left(E_{\mathrm{rm}}\right)$ is also linked to the rock mass strength $\left(\sigma_{\mathrm{cm}}\right)$, deformation modulus for the intact rock $(E)$ and intact rock strength $\left(\sigma_{\mathrm{ci}}\right)$ defined by Eq. (7) suggested 


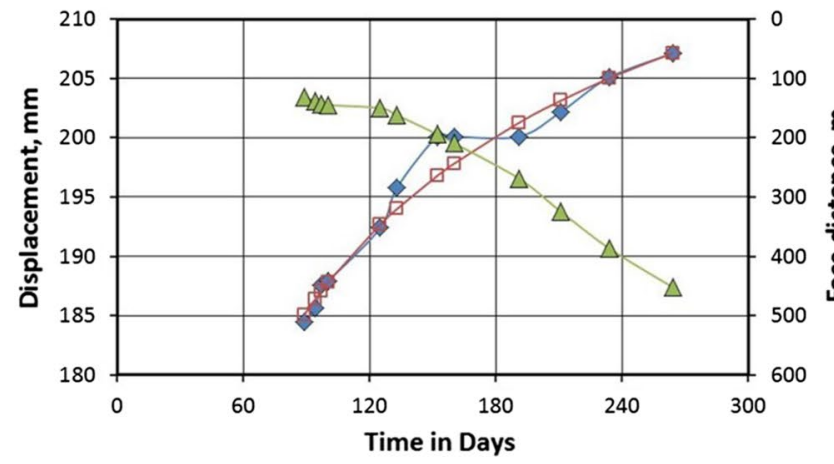

(a) Chainage $0+607 \mathrm{~m}$

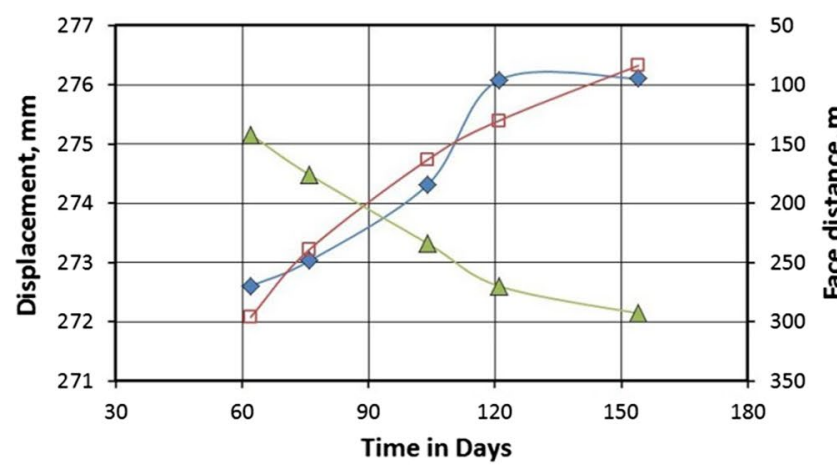

(c) Chainage $5+191 \mathrm{~m}$

$\curvearrowright-$ Measured displacement

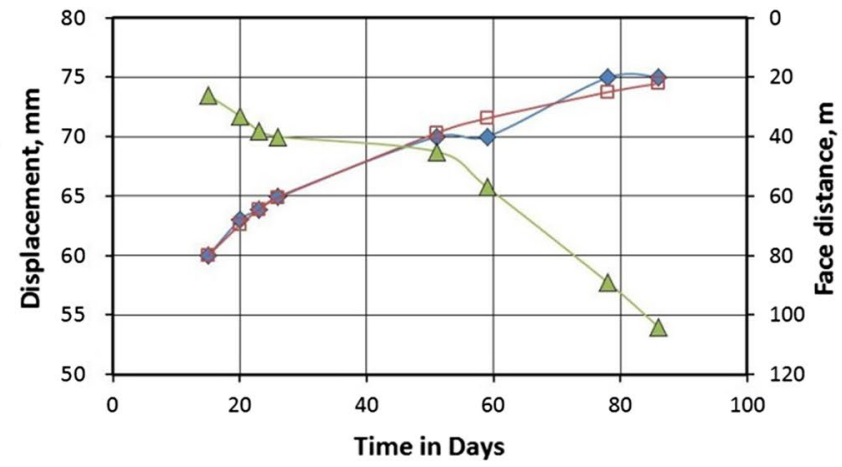

(b) Chainage $0+712 \mathrm{~m}$

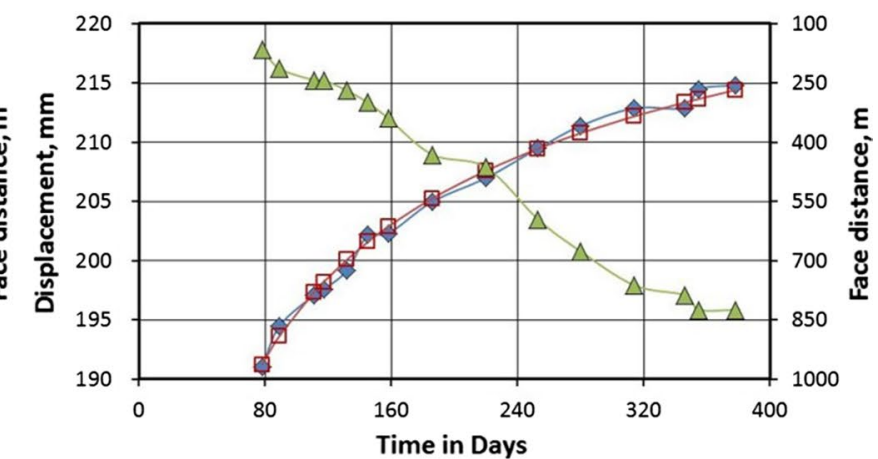

(d) Chainage $6+727 \mathrm{~m}$

$\triangle$ tunnel advance

Fig. 7 Computed and actually measured deformations in the Khimti tunnel sections (Shrestha and Panthi 2014a)

by Panthi (2006). Further, the rock mass strength is linked with cohesion $(c)$ and angle of international friction $(\phi)$ as defined by Eq. (8) proposed by Hoek and Brown (1997).

$G=\frac{E_{\mathrm{rm}}}{2(1+\vartheta)}$

$E_{\mathrm{rm}}=E \times\left(\frac{\sigma_{\mathrm{cm}}}{\sigma_{\mathrm{ci}}}\right)$

$\sigma_{\mathrm{cm}}=\frac{2 c \times \cos \emptyset}{1-\sin \emptyset}$

The author's findings is that in addition to the in situ stress condition and support pressure, the most relevant rock mass parameter is the shear modulus $(G)$, which should be linked with tunnel strain calculation.

\section{Rock Type and Time-Dependent Deformation}

Based on the results presented in Table 5 and using Eqs. (1-3), time-independent and time-dependent deformation for each of the tunnel sections was computed. It was identified that the time-dependent deformation is a significant component of the total deformation in most of the tunnel sections and it varied according to the time span. The maximum time-dependent deformation component (computed as $m C_{\infty x} / \mathrm{FC}$ ) at Kaligandaki tunnel sections varied from 23 to $69 \%$ with a typical average value of $45 \%$, whereas at the Middle Marsyangdi tunnel sections it varied from 15 to $65 \%$ with a typical mean of $37 \%$ and at Khimti tunnel sections it varied from 16 to $83 \%$ with an average of $53 \%$ (Fig. 10).

The calculations also showed that the percentage of time-dependent deformation varied according to the tunnel excavation duration. Increment rate of such deformation was rapid at the early period of the tunnel excavation, and once the time period elapsed, the increment was found to be less and less (Fig. 11).

The extent of time effect in tunnel deformation is also influenced by the rock type. The time effect was found 
Table 5 Computed instantaneous and timedependent variables

\begin{tabular}{lllllllllll}
\hline Chainage (m) & $C_{\infty x x}(\mathrm{~mm})$ & $m$ & $T$ (days) & $X \mathrm{~m}$ & $X / D$ & $n$ & $\mathrm{FC}(\mathrm{mm})$ & $\mathrm{FC} / C_{\infty x x}$ & $\begin{array}{l}\text { Average } \\
\text { error } \\
(\%)\end{array}$ & $\begin{array}{l}\text { Sum of } \\
\text { square of } \\
\text { errors }\end{array}$
\end{tabular}

Kaligandaki headrace tunnel

$\begin{array}{rrrrrrrrrrr}0+611 & 16 & 2.24 & 13.4 & 9.5 & 1.4 & 0.30 & 53 & 3.31 & -2.3 & 0.13 \\ 0+629 & 115 & 0.42 & 16.3 & 18.0 & 2.6 & 0.30 & 163 & 1.42 & 3.6 & 0.12 \\ 0+655 & 44 & 0.92 & 6.1 & 11.8 & 1.7 & 0.30 & 85 & 1.93 & -2.8 & 0.03 \\ 0+700 & 92 & 0.77 & 1.6 & 14.2 & 2.1 & 0.30 & 163 & 1.77 & 0.4 & 0.03 \\ 0+739 & 135 & 0.89 & 1.2 & 15.3 & 2.3 & 0.30 & 254 & 1.88 & 8.3 & 1.25 \\ 0+763 & 103 & 0.60 & 4.5 & 14.8 & 2.2 & 0.30 & 164 & 1.59 & -0.3 & 0.52 \\ 0+799 & 72 & 0.89 & 7.7 & 14.8 & 2.2 & 0.30 & 136 & 1.89 & -0.9 & 0.02 \\ 0+844 & 31 & 0.50 & 5.5 & 11.2 & 1.6 & 0.30 & 47 & 1.52 & -4.5 & 0.09 \\ 0+912 & 35 & 0.94 & 5.0 & 12.0 & 1.4 & 0.30 & 67 & 1.91 & 0.6 & 0.22 \\ 0+977 & 63 & 1.40 & 5.8 & 14.2 & 1.6 & 0.30 & 151 & 2.40 & -4.6 & 1.97 \\ 1+009 & 48 & 1.98 & 9.0 & 13.8 & 1.6 & 0.30 & 144 & 3.00 & -0.5 & 0.16 \\ 1+107 & 27 & 1.02 & 4.8 & 9.8 & 1.1 & 0.30 & 54 & 2.00 & -0.8 & 0.08 \\ 1+147 & 58 & 0.48 & 3.2 & 15.0 & 1.7 & 0.30 & 85 & 1.47 & -0.4 & 0.08 \\ 1+194 & 29 & 0.30 & 8.0 & 19.3 & 2.2 & 0.30 & 37 & 1.28 & 0.1 & 0.12\end{array}$

Middle Marsyangdi headrace tunnel

$\begin{array}{rrrrrrrrrrr}0+451 & 32 & 0.92 & 2.6 & 9.8 & 1.5 & 0.30 & 61 & 1.91 & 2.9 & 0.06 \\ 0+774 & 55 & 0.18 & 2.8 & 12.4 & 1.9 & 0.30 & 64 & 1.16 & 2.5 & 0.06 \\ 1+671 & 58 & 0.33 & 1.0 & 15.9 & 2.4 & 0.30 & 77 & 1.33 & 2.3 & 0.27 \\ 2+832 & 61 & 0.64 & 1.0 & 17.0 & 2.6 & 0.30 & 100 & 1.64 & -0.9 & 0.24 \\ 3+028 & 48 & 0.22 & 1.1 & 14.8 & 2.0 & 0.30 & 59 & 1.23 & -0.1 & 0.17 \\ 3+449 & 17 & 1.89 & 5.5 & 8.6 & 1.3 & 0.30 & 48 & 2.82 & -2.9 & 0.07\end{array}$

Khimti headrace tunnel

$\begin{array}{lrlllllllll}0+607 & 46 & 4.81 & 3.2 & 2.9 & 0.7 & 0.30 & 267 & 5.80 & 0.18 & 0.06 \\ 0+712 & 46 & 1.20 & 7.6 & 3.5 & 0.8 & 0.30 & 101 & 2.19 & 0.06 & 0.09 \\ 5+191 & 243 & 0.19 & 1.8 & 7.5 & 1.5 & 0.30 & 289 & 1.19 & 0.03 & 0.001 \\ 6+727 & 107 & 1.37 & 4.7 & 7.5 & 1.8 & 0.30 & 254 & 2.37 & 0.00 & 0.00\end{array}$

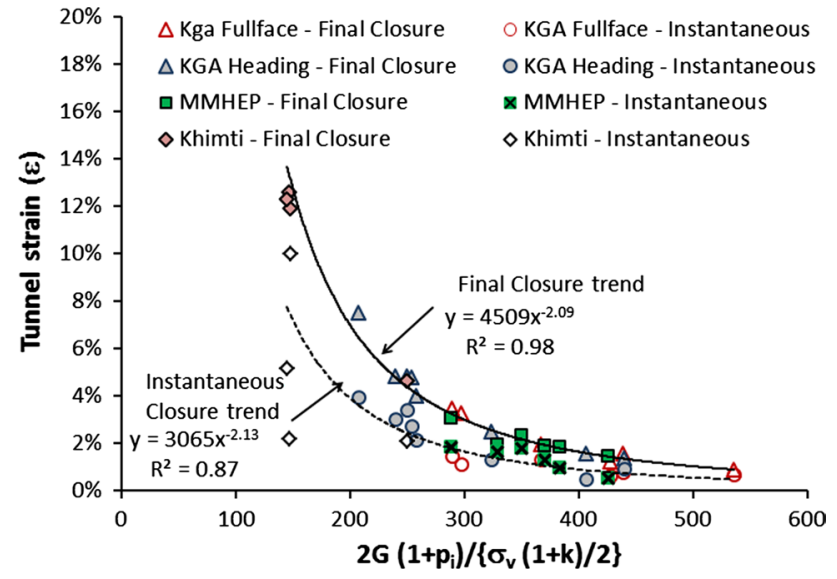

Fig. 8 Correlation of instantaneous and final closure with rock mass property, support pressure and in situ stress (Shrestha 2014)

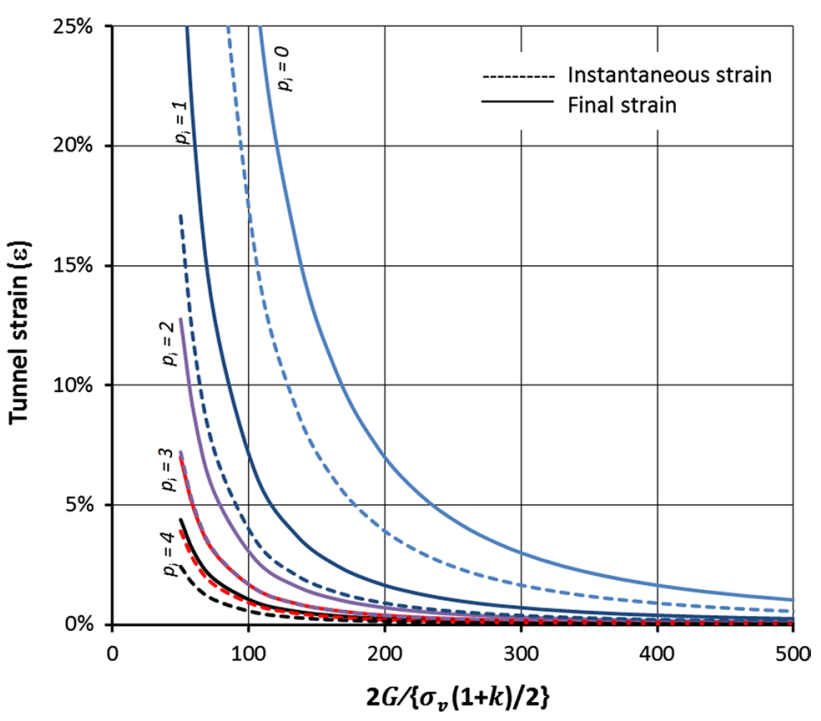

Fig. 9 Tunnel strain versus rock mass shear modulus, in situ stresses for different support pressure magnitude (Shrestha 2014) 


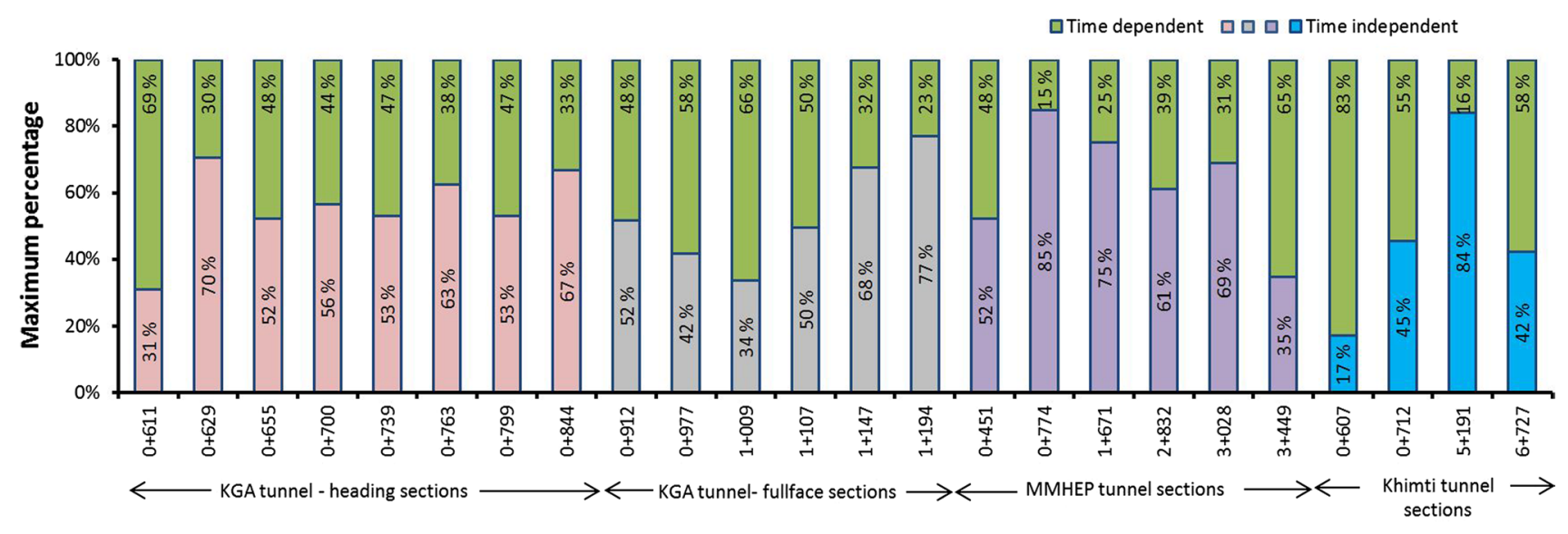

Tunnel Chaianges (m)

Fig. 10 Maximum percentage of time-independent and time-dependent deformations (Shrestha 2014)

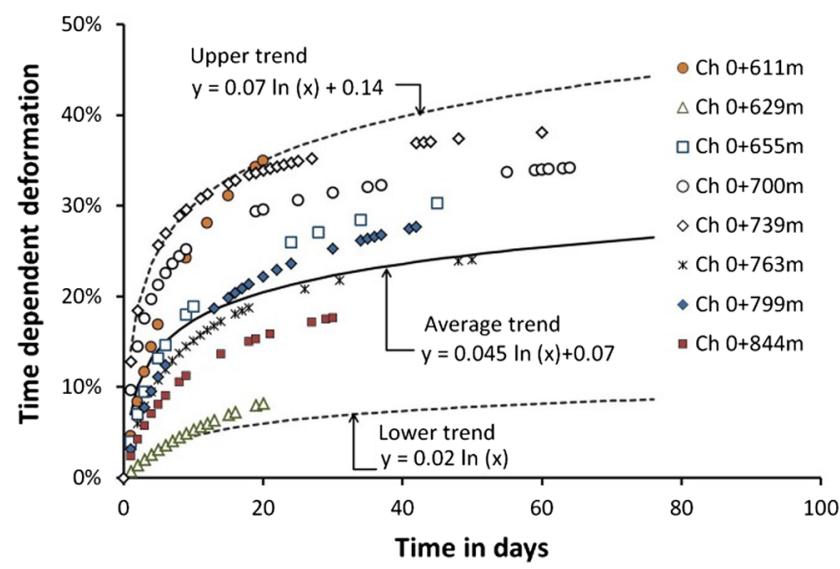

(a) Kaligandaki tunnel - heading sections

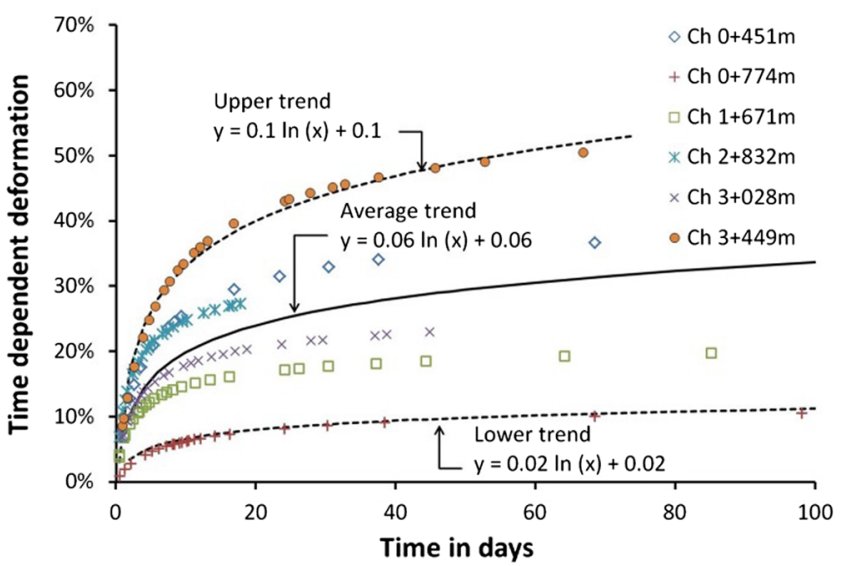

(c) Middle Marsyangdi tunnel sections

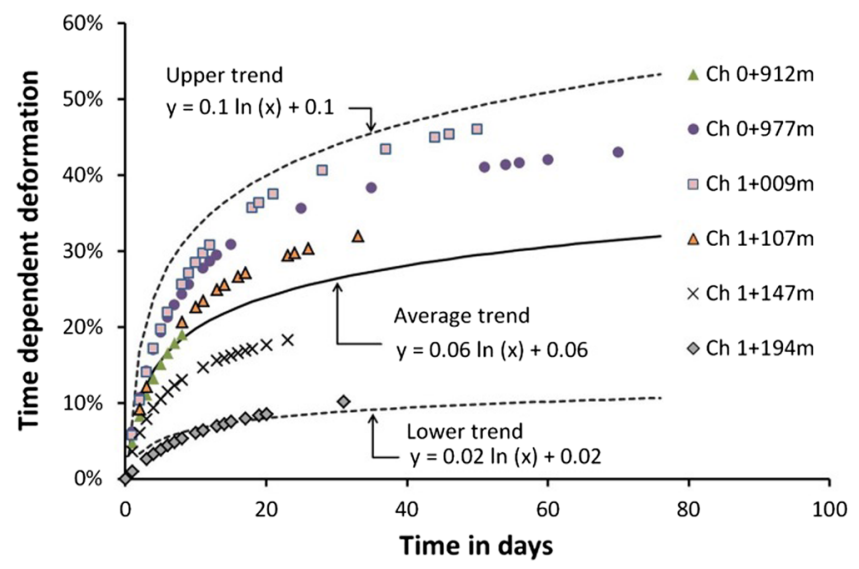

(b) Kaligandaki tunnel fullface sections

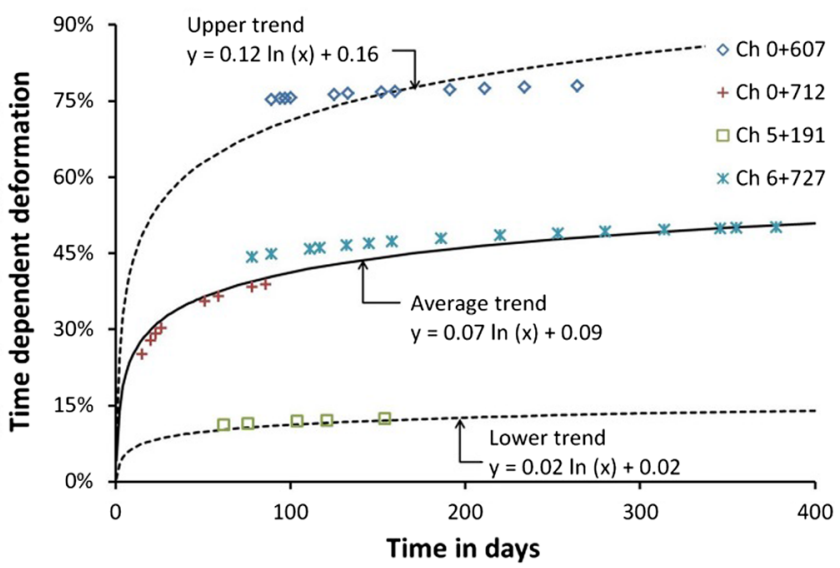

(d) Khimti tunnel sections

Fig. 11 Percentage of time-dependent deformation in total tunnel deformation (Shrestha 2014) 
to be higher in schist and schistose mica gneiss rocks of Khimti tunnel sections, particularly at Chainage $0+607 \mathrm{~m}$ and Chainage $6+727 \mathrm{~m}$, whereas the augen mica gneiss at Chainage $5+191 \mathrm{~m}$ had less effect. Similarly, the time effect in total tunnel deformation was found to be higher in the micaceous phyllite of the Middle Marsyangdi tunnel sections at Chainage $2+832 \mathrm{~m}$ and Chainage $3+449 \mathrm{~m}$, whereas tunnel sections with siliceous phyllite at Chainage $0+774 \mathrm{~m}$ and Chainage $1+671 \mathrm{~m}$ had less time effect. On the other hand, at the Kaligandaki tunnel sections excavated with heading and benching in graphitic phyllite and the full-face excavated tunnel sections in siliceous phyllite have varying degree of time effect in the total deformation. In general, the average trend of the time effect in tunnel deformation was found to have similar trends as indicated in Fig. 11.

\section{Conclusion}

A comprehensive assessment of the recorded plastic deformation of the selected headrace tunnel sections helped to understand on how stress anisotropy plays an important role in the extent of rock mass deformation in the tunnel periphery. The study also has demonstrated that the timeindependent and time-dependent deformations components can be estimated using recorded deformation, time of excavation and tunnel face distances by using Sulem et al. (1987a, b) approach. It is highlighted that the time-independent deformation is mostly dominating and often the most crucial part of the plastic deformation, which takes place immediately after the tunnel excavation and until the tunnel face effect is ceased. Therefore, the preliminary tunnel support effect should be considered while analyzing the maximum extent of the time-independent deformation. Similarly, the additional tunnel support should be applied considering the extent of time-dependent plastic deformation and long-term stability of the tunnel in consideration. This study has confirmed that the time-dependent plastic deformation contributions is substential in the recorded total deformations and it varies according to the engineering geological conditions along the tunnel alignment. The most important part of this analysis was that the authors have found out a correlation between time-independent (instantaneous) and time-dependent (final) rock mass deformation (tunnel strain) with rock mass deformability properties, in situ stress anisotropy and support pressure. The authors emphasize that the suggested relationship should be used to estimate plastic deformation in tunnels passing through highly schistose rock mass as of in the Himalaya.
Open Access This article is distributed under the terms of the Creative Commons Attribution 4.0 International License (http://creativeco mmons.org/licenses/by/4.0/), which permits unrestricted use, distribution, and reproduction in any medium, provided you give appropriate credit to the original author(s) and the source, provide a link to the Creative Commons license, and indicate if changes were made.

\section{References}

Barton NR, Lien R, Lunde J (1974) Engineering classification of rock masses for the design of tunnel support. Rock Mech 16(4):189-239

Bieniawski ZT (1973) Engineering classification of jointed rock masses. Trans S Afr Inst Civil Eng 15:335-344

Bieniawski ZT (1989) Engineering rock mass classifications. In: A complete manual for engineers and geologists in mining, civil and petroleum engineering. Wiley, New York, p 251

Bieniawski Z (1993) Classification of rock masses for engineering: the RMR-system and future trends. Comprehensive rock engineering. J. A. Hudson ed. 3:553-573

Carranza-Torres C, Fairhurst C (2000) Application of the convergence-confinement method of tunnel design to rock-masses that satisfy the Hoek-Brown failure criterion. Tunn Undergr Space Technol 15(2):187-213

Fairhurst C, Carranza-Torres C (2002) Closing the circle: Some comments on design procedures for tunnel supports in rock. In: Labuz JF, Bender JG (eds) Proceedings of the University of Minnesota 50th Annual Geoteehmical Conference, University of Minnesota Press, Minneapolis, pp 21-84

Grimstad E, Barton N (1993) Updating the Q-system for NMT. In: Proceeding of the international symposium on spraid concretemodern use of wet mix sprayed concrete for underground support, pp 46-66

Hoek E (1994) Strength of rock and rock masses. News J ISRM 2(2):4-16

Hoek E (2007) Practical rock engineering. https://www.rocscience .com/learning/hoek-s-corner

Hoek E, Brown ET (1997) Practical estimates of rock mass strength. Int J Rock Mech Min Sci Geomech Abstr 34(8):1165-1186

Hoek E, Marinos P (2000) Predicting tunnel squeezing problems in weak and heterogeneous rock masses. Tunn Tunn Int 32(11):4551 and 32(11):34-46

Kontogianni V, Psimoulis P, Stiros S (2006) What is the contribution of time-dependent deformation in tunnel convergence? Eng Geol 82:264-267

Nepal KM (1999) A review of in situ testing of rock mechanical parameters in hydropower projects of Nepal. J Nepal Geol Soc 19:1-8

Nepal Electricity Authority (NEA) (2002) Project completion report. Volume I-C, Headrace Tunnel, Volume IV-A, Geology and Geotechnical, Volume V-C Geological Drawings and Exhibits, Kaligandaki 'A' Hydroelectric Project, Nepal

Nepal Electricity Authority (NEA) (2011) Project completion report. Volume 6C, Geology and Geotechnical Report, Middle Marsyangdi Hydroelectric Project (MMHEP), Nepal

Oreste P (2009) The convergence-confinement method: roles and limits in modern geomechanical tunnel design. Am J Appl Sci 6(4):757-771

Panet M (1995) Le calcul des tunnels par la méthod convergenceconfinement. Presses de I'ENPC, Paris

Panet M (2001) Recommendations on the convergence confinement method. Association Francaise des Travaux en Souterrain (AFTES), Paris 
Panthi KK (2006) Analysis of engineering geological uncertainties analysis related to tunnelling in himalayan rock mass conditions. Doctoral Thesis at NTNU 2006:41, Department of Geology and Mineral Resources Engineering, Norwegian University of Science and Technology, Norway. ISBN 82-471-7826-5

Panthi KK (2012) Evaluation of rock bursting phenomena in a tunnel in the Himalayas. Bull Eng Geol Environ 71:761-769

Panthi KK, Nilsen B (2007a) Predicted versus actual rock mass conditions: a review of four tunnel projects in Nepal Himalaya. Tunn Undergr Space Technol 22(2):173-184

Panthi KK, Nilsen B (2007b) Uncertainty analysis of tunnel squeezing for two tunnel cases from Nepal Himalaya. Int J Rock Mech Min Sci 44:67-76

Shrestha PK (2014) Stability of tunnels subject to plastic deformation-a contribution based on the cases from the Nepal Himalaya. Doctoral Thesis at NTNU 2014:305, Norwegian University of Science and Technology, Norway. ISBN 978-82-326-0522-4

Shrestha PK, Panthi KK (2014a) Analysis of plastic deformation behavior of schist and schistose mica gneiss at Khimti headrace tunnel, Nepal. Bull Eng Geol Environ 73:759-773
Shrestha PK, Panthi KK (2014b) Assessment of the effect of stress anisotropy on tunnel deformation in the Kaligandaki Project in the Nepal Himalaya. Bull Eng Geol Environ. https://doi.org/10.1007/ s10064-014-0641-5

Sulem J, Panet M, Guenot A (1987a) Closure analysis in deep tunnels. Int J Rock Mech Min Sci Geomech 24(3):145-154

Sulem J, Panet M, Guenot A (1987b) Analytical solution for time dependent displacements in a circular tunnel. Int J Rock Mech Min Sci Geomech 24(3):155-164

Vlachopoulos N, Diederichs MS (2009) Improved longitudinal displacement profiles for convergence confinement analysis of deep tunnels. Rock Mech Rock Eng 42(2):131-146

Wang HN, Utili S, Jiang MJ (2014) An analytical approach for the sequential excavation of axisymmetric lined tunnels in viscoelastic rock. Int J Rock Mech Min Sci 68:85-106 